\title{
Yeast-Worm-Animal Similarities in Insulin-Like Receptors and Signal Transduction: The Aging Pathway Goes Through Insulin Signaling
}

\begin{abstract}
A review of: Clancy DJ, Gems D, Harshman LG, et al. 2001 Extension of life-span by loss of CHICO, a drosophila insulin receptor substrate protein. Science 292:104-106; and Tatar M, Kopelman A, Epstein D, et al. 2001 A mutant drosophila insulin receptor homolog that extends life-span and impairs neuroendocrine function. Science 292:107-110
\end{abstract}

$\mathrm{T}$ HE CONTROL OF cell growth and metabolism is critically important to the developing organism. Recently, the discovery of the drosophila homologs for the Insulin Receptor, InR, and the Insulin Receptor Substrate 1 gene, nicknamed chico, has lead researchers to ask whether mutations in either gene alters growth and developmental processes in these organisms. The answer is of course, yes. In worms (1), flies (2), and in transgenic mice (3), mutations in the insulin signaling pathway reduce growth and size of the organism. Curiously, during the course of these studies it was discovered that in flies longevity was prolonged by $48 \%$ in female chico mutants and by $85 \%$ in InR mutants. Both mutations stalled or blocked reproduction, suggesting that hormonal signals that regulate growth and reproduction may also play a role in lengthening life span.

The insulin signaling pathway activates two major branches: the Ras/Map Kinase pathway and the IRS1/phosphoinositide 3-kinase/Akt pathway. Mutations in chico in the fly or in the insulin/ IGF-I-like receptor signaling pathway in the worm C-elegans also results in increased accumulation of fat $(2,4)$, and promoted the resistance to starvation, suggesting a relationship between longevity and energy storage. Restoring the PI 3-kinase signaling pathway to muscle rescued the metabolic defects, but not longevity. However restoration of the pathway in neurons did both (5). These

\section{JACOB E. FRIEDMAN}

studies point to insulin signaling in the central nervous system as a key regulator of both longevity and conservation of growth and metabolism in a broad range of species.

Unlike mammals, drosophila make a single hybrid insulin/IGF-1 receptor, however there is evidence for a role of IGF-1 in longevity and growth in mice, dogs and possibly primates (6). It is also possible that these same genes may independently regulate growth during the preadult period as well as survival during adulthood. Caloric restriction during adulthood has long been known to increase longevity and decrease IGF-1 and insulin levels without an effect on body size. Indeed when food is scarce, adult animals typically enter into a semi-dormant state allowing them to survive periods of food deprivation. Similarly, overexpression of growth hormone or IGF-1 levels in transgenic mice tends to decrease life span. These results support the idea the insulin-like signaling pathway and its control of metabolic activity are likely to be a general regulator of the rate of aging, as well as growth and reproduction.

In humans, homozygous mutations for the insulin receptor tend to be lethal, and combinations of insulin receptor and IGF-1 mutations are very rarely reported. While mutations in the insulin signaling pathway can lead to diseases such as diabetes and obesity, the fact that conserving resources can lead to enhanced longevity, and these processes use the same signaling pathway, suggests that modulation of insulin-like signaling processes in-utero could be important determinants of future metabolic activity, including aging. Connecting these pathways with alterations in the amounts of hormones, their function, and environmental conditions will increase our understanding about how insulin signaling affects not only growth and development but also possibly regulation of aging.

\footnotetext{
1. Kimura KD,. Tissenbaum HA, Liu Y, Ruvkun, G 1997 daf-2, an insulin receptor-like gene that regulates longevity and diapause in caenorhabditis elegans. Science 277: 942-946.

2. Tatar M, Kopelman A, Epstein D, Tu MP, Yin CM, Garofalo RS 2001 A mutant drosophila insulin receptor homolog that extends life-span and impairs neuroendocrine function. Science 292:107-110 .

3. Tamemoto H, Kadowaki T, Tobe K, Takeshi Y, Sakura H, Hayakawa T, Terauchi Y, Ueki K, Kaburagi Y, Satoh S, Sekihara H, Yoshioka S, Horikoshi H, Furuta Y, Ikawa Y, Kasuga M, Yazaki Y, Aizawa S 1994 Insulin resistance and growth retardation in mice lacking insulin receptor substrate-1. Nature 372:182-186.

4. Albert PS, Riddle DL 1988 Mutants of caenorhabditis elegans that form dauer-like larvae. Dev Biol 126: 270-293.

5. Wolkow CA, Kimura KD, Lee M-S, Ruvkun G 2000 Regulation of C. elegans life-span by insulinlike signaling in the nervous system. Science 290:147-150.

6. Roth GS, Ingram DK, Black A, Lane MA 2000 Effects of reduced energy intake on the biology of aging: the primate model. Eur J Clin Nutr 54 (suppl 3):S15-S20.
}

University of Colorado Health Sciences Center Department of Pediatrics, Biochemistry \& Molecular Genetics

4200 E. 9th Avenue, B-195

Denver, CO 80262, U.S.A. 